\title{
A Researchon Influence of Admixtureson Mechanical Properties of Fibre Reinforced Concrete
}

\author{
Pulisai,G.B. Ramesh Kumar
}

\begin{abstract}
In this paper presents the mechanical properties of the fiber reinforced concrete. For that the experimental work should be done by using natural fiber that is coir ond it should be done on by using $\mathrm{M5O}$ grade of concrete. In this project we are going to use the admixtures also at different percentages by the replacement of the cement material. By adding the admixtures the characteristic strength of the concrete also improved when compared to the normal concrete. The mechanical properties like the compression strength, flexural strength, density and ductility of theconcrete be calculated in this experimental work the coir fiber was added up to the $0.4 \%$ of the binder volume of the concrete mixture. In this work the admixtures like flyash and silica fumealso mixed at $10 \%$ and $20 \%$ respectively. By using this experimental work, ductility, modulus of elasticity and ultra pulse value ofreinforced concrete also determined.
\end{abstract}

Key words - Modulus of elasticity,ultra pulse value, silica fume and flyash.

\section{INTRODUCTION}

High srength concretehas been very used to develop the mechanical properties of the concrete. It should be based on the choosing of the chemical admixtures for the concrete mixture and it should be widely used in the construction of the heavy industries. These chemical admixtures should be used to develop the mechanical properties of the concrete mixture like the compression strength of the concrete and it should be liesbetween 50 to $80 \mathrm{Mpa}$.

Nearly entirely these concretes takinginorganic additives contain for a change of motives of withassetimprovement , discount of penetrability ,higher crack resistance and strength factors .such as silica fume and fly ashhave a important talent in this situation.

The durability of the concrete mixture should been plays an important role in the field of the high strength concrete. Theultra pulse velocity is should used to be develop the durability of the concrete.

\section{LITERATURE REVIEW PAPER}

In this paper, coconut fibers were cast-offeasily existing in huge measures .Basically amongall the fiber materials are extensively used in the concrete field work plastic fiber and nylon fiberetc., but the natural fiber is widely available at everywhere for the cheap cost only. Coir fiber is particularly used in this project work because of it is one of the thermal conductivity material. It is used to determine the optimal

Revised Manuscript Received on April 12, 2019.

Pulisai, M.E. Structural Engineering, Civil DepartementSaveetha School of Engineering, Chennai, T.N, India. (E-mail: pulisaireddy1919@gmail.com)

Dr. G.B. Ramesh Kumar, M.E.,Ph.D,Associate Professor of Structural EngineeringSaveetha School of Engineering, Chennai, T.N, India. (E-mail: rameshkumargb@gmail.com) choice to the fortitude contented thefiber reinforced concrete material. These fiber materials should be cut in to the 20 $\mathrm{mm}$ size and then used for the concrete mix design.

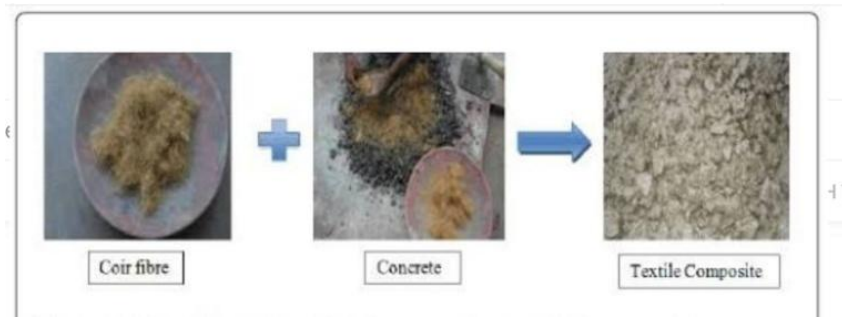

Fig: Coir fibre mixed with concrete as reinforcement

\section{LITERATURE REVIEW PAPER}

In this study, short distinct fibres specifically jute, fibre and bamboo has been examined for his or her quality for incorporation in cement concrete. The fleshly belongings of those fibers have shown no corrosionin a concrete medium. it's shown that viable and same mixes is obtained employing a special technique of proportioning. whereas compressive and tensile strengths of fiber concretes aren't any beyond those of management concrete their deformationcomportment shows improvement in malleabilityand shrinkage .Impact and fracture toughness of fiberconcretes are clearly higher.

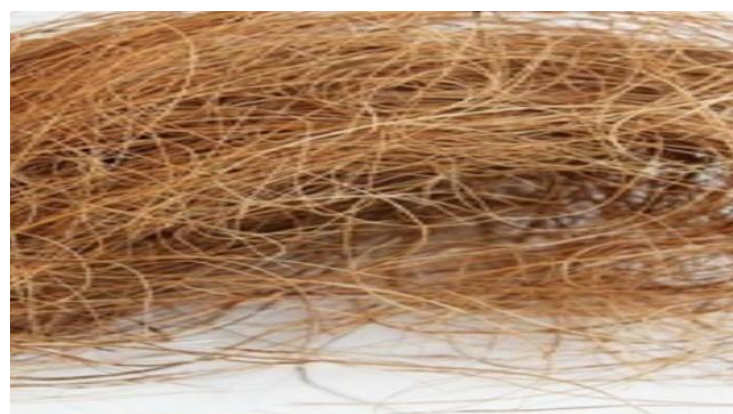

\section{LITERATURE REVIEW PAPER}

In this studies, fiber ferroconcrete is step by step used in construction work . Analysisof fibres andmethod releated to housing $\mathrm{i}$ have adult apace. The advantage of different concrete materials measure thier high durability to magnitude relation. Themoulded in to cubes and cylinders, leading to doubtless low value. The properties build fibre ferroconcrete composite is used for various project works .

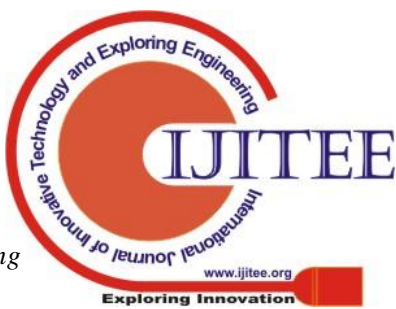


A comparisons of strength properties of fiber ferroconcrete is formed with relevancy standeredconcretemixture.Inthis ,square measurefor exploitation processed coconut fibers .

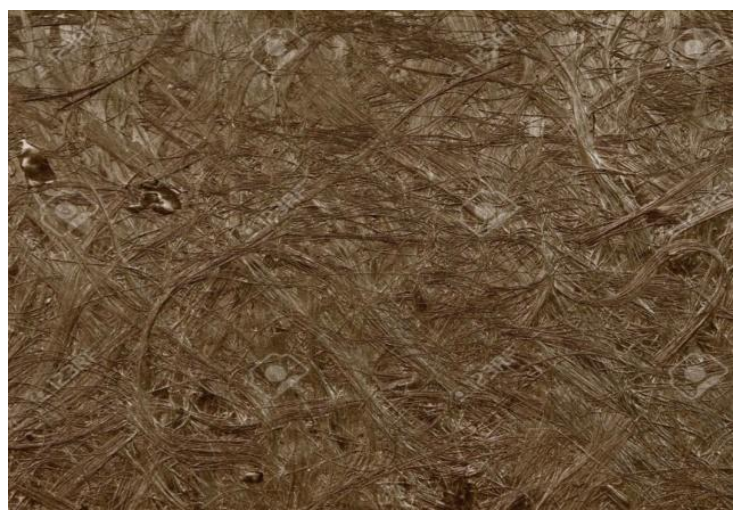

\section{LITERATURE REVIEW PAPER\& RESULT DISCUSSION}

In this study, we should introduce the different admixturesfor the different proportions because of to attain the compression strength and flexural strengthof the concrete mix proportions. In this mainly the natural coir fiber is plays an important role to forwarded the project work because it only produce the electronic conductivity of the material.

By using the artificial coir fiber the strength of the material should be very less when compared to the natural coir fiber material.Particularly this kind of materials improves the strength of the concrete when compared to the normal concrete.

NATURAL FIBRE (COIR)

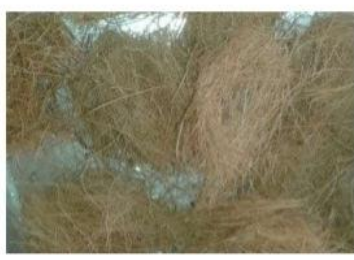

ARTIFICIAL FIBRE (NYLON)

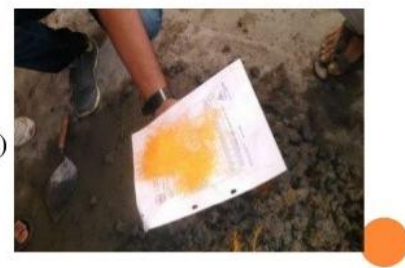

\section{REFERENCES}

1. Vanchaisata,chaijaturapitakkul,kraiwoodkiattikomol., Vol 21,(2007),1589-159

2. kraiwoodkiiattikomol,Vanchaisata,

Theerarachleekeeratikul.,Vol.34 , (2004), 549-555.

3. Rafatsiddique., Vol .34, (2004), 487-493.

4. kyoungGwang.Vol.15 NO. 5 , 747-758. 